\title{
Ulnar Nerve Conduction Abnormalities in Turkish Taxi Drivers
}

\author{
Sevgi İkbali AFŞAR ${ }^{1}$, Nuri ÇETİN', Şehri AYAŞ¹, Gamze Akın MUMCU², Metin KARATAŞ¹ \\ ${ }^{1}$ Department of Physical Medicine and Rehabilitation, Medical Faculty of Başkent University, Ankara, Turkey \\ ${ }^{2}$ Department of Physical Medicine and Rehabilitation, Balikesir Physical Therapy Center, Balıkesir, Turkey
}

\begin{abstract}
Objectives: This study aims to investigate the presence of ulnar entrapment neuropathy at the elbow in taxi drivers, and possible relationship between ulnar entrapment neuropathy and habitually leaning the left elbow on the lower edge of the window.

Patients and methods: The study was performed between December 2008 and February 2009 in Ankara and included 40 male taxi drivers (mean age $35.5 \pm 7.3$ years; range 25 to 54 years) and 40 healthy male controls (mean age $33.6 \pm 6.1$ years; range 25 to 54 years). Nerve conduction studies were performed on both upper limbs of all participants.

Results: Left side motor and sensory nerve conduction velocities at the elbow segment of the ulnar nerve were significantly decreased, while $F$ latency of the ulnar nerve was significantly prolonged in taxi drivers. Motor and sensory conduction velocity over both left and right ulnar nerve at the elbow segment were significantly decreased, while F latency of the ulnar nerve was significantly prolonged in the taxi drivers compared to the control group. Ulnar nerve conduction parameters and F latency on both sides were statistically similar in the non-leaning group of taxi drivers; however, motor and sensory conduction studies over the left side of the ulnar nerve elbow segment were slower and F latency was longer in the leaning group of taxi drivers, compared to the right side and to the non-leaning group of taxi drivers.

Conclusion: Prolonged elbow flexion and habitually leaning the left elbow may cause electrodiagnostically diagnosed ulnar entrapment neuropathy in taxi drivers.

Keywords: Elbow flexion; electrophysiology; taxi driver; ulnar entrapment neuropathy.
\end{abstract}

Although the precise incidence and prevalence remains unknown, ulnar entrapment neuropathy at the elbow (UNEE) is the second most common peripheral entrapment neuropathy, following carpal tunnel syndrome.1,2 According to an Italian study, the annual incidence of UNEE was 20.9/100,000 which increases with age. ${ }^{3}$ The incidence in men was twice as high as in women, moreover it was reported to occur more frequently in geographic regions where manual labor is common. ${ }^{3}$

Compression, traction, and subluxation/ dislocation of the ulnar nerve at the cubital tunnel during prolonged elbow flexion or repetitive elbow flexion and extension are associated with the pathomechanics of UNEE. ${ }^{4}$ Furthermore, direct mechanical pressure on the ulnar nerve negatively affects the blood supply of the nerve, and local ischemia is the end result that causes the neuropathy. ${ }^{5}$

The etiology of UNEE is multifactorial. Although some specific types of work have been reported to cause UNEE, it has not yet been definitively proven. ${ }^{6}$ Employees working with flexed elbows such as carpenters, artists, glass cutters, telephone switchboard workers, tailors and musicians have a high risk of developing UNEE. Repetitive elbow motion, prolonged elbow flexion, and direct pressure on the ulnar nerve increase the risk of UNEE in these occupations. ${ }^{7,8}$ The typical cause is prolonged flexion of the elbow with the resultant nerve traction and direct ulnar nerve trauma at the elbow, when the driver leans heavily on his elbow, thereby compressing

\footnotetext{
Received: April 11, 2013 Accepted: June 22, 2013

Correspondence: Sevgi İkbali Afşar, M.D. Başkent Üniversitesi Tıp Fakültesi Fizik Tedavi ve Rehabilitasyon Anabilim Dalı, 06490 Bahçelievler, Ankara, Turkey. Tel: +90 312 - 2126650 e-mail: ikbaliafsar@hotmail.com
}

(2014 Turkish League Against Rheumatism. All rights reserved. 
the ulnar nerve during its superficial path. ${ }^{9}$ The present study aims to examine UNEE in taxi drivers, and the relationship between UNEE and habitually leaning the left elbow on the lower edge of the window.

\section{PATIENTS AND METHODS}

In this research, sample power was evaluated as 98\% using the Power and Sample Size (PASS) Software Program, version 11 (PASS-11, NCSS, LLC, Kaysville, Utah, USA, 2011). The study was performed between December 2008 and February 2009 in Ankara and included 40 male taxi drivers (mean age $35.5 \pm 7.3$ years; range 25-54 years)

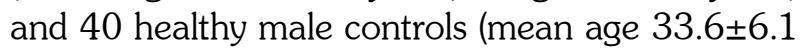
years; range 25 to 54 years) without a previously described risk for ulnar entrapment neuropathy. Exclusion criteria were systematic disorders such as diabetes mellitus, chronic renal failure, chronic alcoholism, and gout, a history of polyneuropathy, radiculopathy, myelopathy, brachial plexopathy, or other neurological disease, and a history of surgery for ulnar entrapment neuropathy, acute traumatic ulnar neuropathy, or fracture at the elbow. In addition, both taxi drivers and control subjects were screened for common behaviors and symptoms associated with ulnar entrapment such as extensive phone use with phone held to the ear, hyperflexion of the elbow at night in bed, intermittent numbness of the medial palm and/or fifth digit.

Demographic characteristics of the taxi driver and control groups were recorded. The taxi drivers' working hours per week and working weeks per year and information about habitual leaning of their left elbow on the edge of the car door were also recorded. All the participants provided written informed consents. The study was approved by the institution Ethics Committee and carried out according to the institutional guidelines and principles of the Declaration of Helsinki.

All the participants underwent electrophysiological evaluation performed by a single physiatrist. Bilateral upper extremities were evaluated. Conventional motor and sensory conduction studies of the median and ulnar nerves and sensory conduction studies of the radial nerve were performed.
The compound muscle action potentials (CMAP) were recorded using $9 \mathrm{~mm}$ disc surface cup $(\mathrm{Ag} / \mathrm{AgCl})$ electrodes (TECA Accessories, Medelec, Oxford instruments, Old Woking, UK) placed over the motor point of the abductor pollicis brevis muscle for the median nerve and over the abductor digiti minimi muscle for the ulnar nerve. The stimulation intensity was supramaximal. A point $8 \mathrm{~cm}$ distant to the active electrode, the wrist between the flexor carpi radialis and palmaris longus tendons, and the antecubital fossa were used to stimulate the median nerve. The median nerve distal motor latencies, forearm motor conduction velocities, and CMAP amplitudes were recorded. A point at the wrist $8 \mathrm{~cm}$ proximal to the active electrode, a point below the elbow 3-4 cm distal to the medial epicondyle, and a point above the elbow 10-12 cm proximal to the second site were used to stimulate the ulnar nerve. The wrist was kept in the neutral position, while the elbow was kept flexed at 90 degrees during the tests. Ulnar nerve distal motor latencies, CMAP amplitudes, and motor conduction velocities at the forearm and elbow segments were calculated. Distal motor latencies were measured from the time of onset of the potential, while CMAP amplitudes were measured from baseline to the first negative peak of the action potential. $F$ wave studies were performed on the median and ulnar nerves via recordings from the same muscles. At least 20 supramaximal stimulations were administered and the minimum $\mathrm{F}$ latencies were recorded.

Sensory nerve conduction studies were performed antidromically. The median nerve was stimulated at the wrist $12 \mathrm{~cm}$ from the active electrode and from antecubital fossa, and the sensory nerve action potentials (SNAP) were recorded with ring electrode from the third digit. Median nerve distal sensory latencies, SNAP amplitudes, and forearm sensory nerve conduction velocities were recorded. The ulnar nerve was stimulated at the wrist $12 \mathrm{~cm}$ from the active electrode, about 3-4 cm distal to the medial epicondyle (below the elbow), and 10-12 cm proximal to that site (above the elbow). Ulnar nerve distal sensory latencies, SNAP amplitudes, and sensory conduction velocities of the forearm and elbow segments were recorded from the fifth digit using ring electrodes. The lateral border of the radius and $12 \mathrm{~cm}$ proximal point to the active electrode were used for superficial radial nerve 
stimulus and an electrode on the extensor pollicis longus tendon as a reference and one on the second metacarpal head lateral side as a reference were used to record SNAP. Distal sensory latencies were defined as the SNAP peak and amplitudes were measured from peak to peak. Latencies are expressed in milliseconds (ms), CMAP amplitudes as millivolts $(\mathrm{mV})$, and SNAP amplitudes as microvolts $(\mu \mathrm{V})$. Nerve conduction velocities were calculated as $\mathrm{ms}^{-1}$. Filter settings were $3 \mathrm{~Hz}-10 \mathrm{kHz}$ for motor conduction studies and $20 \mathrm{~Hz}-2 \mathrm{kHz}$ for sensory conduction studies.

Examinations were performed using a Medelec $^{\circledR}$ Synergy multimedia electromyograph (Oxford Instruments, Surrey, England). All electrophysiological examinations were conducted at temperatures above $25^{\circ} \mathrm{C}$. The extremity distal skin temperature of each participant was measured at the dorsum of the hand and was maintained above $32{ }^{\circ} \mathrm{C}$. If required, heating was maintained with hot packs.

Electrophysiological diagnosis of UNEE was performed according to the following criteria: (i) an across-elbow ulnar conduction velocity $<50 \mathrm{~ms}^{-1}$; (ii) an across-elbow ulnar conduction velocity decrease of $>10 \mathrm{~ms}^{-1}$ when compared to the forearm $\left(90^{\circ}\right.$ elbow flexion); and (iii) decrease in CMAP amplitude of $>20 \%$ with stimulation above the elbow compared with stimulation below. The presence of all three criteria referred to the definite UNEE, while the presence of two criteria referred to the probability of UNEE. ${ }^{10}$ In the presence of definite or probable UNEE, needle electromyographic examination was performed. Data were analyzed using the SPSS statistics version 11.5 for Windows software program (SPSS Inc., Chicago, IL, USA). The Shapiro-Wilk test was applied to assess assumption of normality for all continuous variables. Comparisons between drivers and the controls were made using the Student's t-test or the nonparametric MannWhitney U test, as appropriate. Comparisons between left and right side electrophysiological measurements of drivers and controls were made using Student's t-test for dependent samples or the Wilcoxon signed rank test, as appropriate. The Fisher's exact test was used for testing the association between qualitative variables. Oneway ANOVA with Tukey's studentized range test was performed to examine the differences of dependent variables among the four groups. The level of statistical significance was set at $\mathrm{p}<0.05$.

\section{RESULTS}

The mean height and weight of the taxi driver group were $1.74 \pm 0.07 \mathrm{~m}$ and $75.2 \pm 9.9 \mathrm{~kg}$, respectively, compared to $1.73 \pm 0.08 \mathrm{~m}$ and $79.1 \pm 11.9 \mathrm{~kg}$, respectively, in the control group. There was no significant difference in demographic data between the two groups.

In the taxi driver group, the mean duration of driving was $12.8 \pm 6.9$ years, the mean week per year was $50.3 \pm 1.5$, and the mean hour per week was $62.0 \pm 15.9$. Among the taxi drivers, 33 (82.5\%) habitually leaned their left elbow on the edge of the car door, and the mean duration of driving

Table 1. Demographic data of taxi drivers who did or not lean their elbow on the edge of the car door

\begin{tabular}{|c|c|c|c|c|c|c|c|}
\hline \multirow[t]{2}{*}{ Variables } & \multicolumn{3}{|c|}{ Did not lean elbow (n=7) } & \multicolumn{3}{|c|}{ Leaned elbow $(n=33)$} & \multirow[b]{2}{*}{$p$} \\
\hline & Mean \pm SD & $\mathrm{n}$ & $\%$ & Mean \pm SD & $\mathrm{n}$ & $\%$ & \\
\hline Age (years) & $33.4 \pm 7.6$ & & & $35.9 \pm 7.2$ & & & 0.413 \\
\hline Height (m) & $1.71 \pm 0.08$ & & & $1.74 \pm 0.07$ & & & 0.345 \\
\hline Weight (kg) & $73.7 \pm 13.6$ & & & $75.5 \pm 9.1$ & & & 0.662 \\
\hline Years worked as a taxi driver & $8.7 \pm 6.3$ & & & $13.7 \pm 6.8$ & & & $0.041^{*}$ \\
\hline Week per year & $50.0 \pm 1.6$ & & & $50.4 \pm 1.5$ & & & 0.601 \\
\hline Hour per week & $56.6 \pm 20.1$ & & & $63.2 \pm 15.0$ & & & 0.382 \\
\hline \multicolumn{8}{|l|}{ Dominant hand } \\
\hline Right & & 7 & & & 31 & & 1.000 \\
\hline Left & & 0 & & & 2 & & 1.000 \\
\hline Present symptoms & & 1 & 14.3 & & 7 & 21.2 & 1.000 \\
\hline
\end{tabular}


Table 2. Comparison of ulnar nerve electrophysiological parameters between and within groups

\begin{tabular}{|c|c|c|c|c|c|c|c|c|c|c|c|c|c|c|}
\hline \multirow[t]{3}{*}{ Variables } & \multicolumn{6}{|c|}{ Control group } & \multirow[b]{3}{*}{$p^{*}$} & \multicolumn{6}{|c|}{ Taxi drivers } & \multirow[b]{3}{*}{$p^{* * *}$} \\
\hline & \multicolumn{3}{|c|}{ Right } & \multicolumn{3}{|c|}{ Left } & & \multicolumn{3}{|c|}{ Right } & \multicolumn{3}{|c|}{ Left } & \\
\hline & Mean \pm SD & Median & Min.-Max. & Mean \pm SD & Median & Min.-Max. & & Mean \pm SD & Median & Min.-Max. & Mean \pm SD & Median & Min.-Max. & \\
\hline DML & & 2.7 & $2.6-2.8$ & & 2.7 & $2.5-2.8$ & 0.038 & & 2.8 & $2.6-3.0$ & & 2.8 & $2.6-3.0$ & 0.621 \\
\hline CMAP & $10.8 \pm 1.6$ & & & $10.0 \pm 2.0$ & & & $<0.001$ & $10.9 \pm 2.0$ & & & $10.5 \pm 1.8$ & & & 0.142 \\
\hline MCVF & $63.2 \pm 3.5$ & & & $63.7 \pm 4.2$ & & & 0.495 & $62.0 \pm 2.9$ & & & $63.1 \pm 4.5$ & & & 0.108 \\
\hline MCVE & & 68.5 & 64.6-73.1 & & 66.7 & $64.1-72.4$ & 0.669 & & 60.0 & $56.4-62.8$ & & 53.7 & $47.6-56.3$ & $<0.001$ \\
\hline MFL & & 26.0 & $25.1-27.0$ & & 26.3 & 25.1-27.2 & 0.904 & & 26.8 & $26.0-27.6$ & & 27.5 & $26.1-28.8$ & $<0.001$ \\
\hline SNAP & & 39.6 & $31.8-60.0$ & & 44.1 & $24.7-58.2$ & 0.851 & & 40.0 & $28.0-50.0$ & & 32.8 & $22.3-46.5$ & 0.245 \\
\hline SCVF & & 64.4 & $60.1-68.7$ & & 64.7 & $62.0-67.6$ & 0.559 & & 62.8 & $60.1-66.7$ & & 64.9 & $61.6-67.8$ & 0.630 \\
\hline SCVE & $69.4 \pm 6.1$ & & & $69.7 \pm 6.1$ & & & 0.740 & $60.7 \pm 6.1$ & & & $54.5 \pm 6.4$ & & & $<0.001$ \\
\hline
\end{tabular}

in these 33 taxi drivers was longer than in those that did not habitually lean their left elbow. The entire control group and 38 of the 40 taxi drivers were right handed. Among the taxi drivers, eight had at least one symptom like numbness, tingling, burning or pain in the distribution of the ulnar nerve. Apart from the duration of driving there were no significant differences in the demographic data between taxi drivers who leaned their left elbow on the edge of the car door and those who did not (Table 1).

Electrophysiological examination showed that radial sensory nerve conduction velocities and SNAP amplitudes were normal in both groups. Median and radial nerve electrophysiological findings did not differ significantly between the taxi drivers and control groups. In the taxi driver group, right side and left side ulnar nerve motor and sensory conduction velocities at the elbow segment were significantly slower, and the ulnar nerve minimum Flatencies were significantly longer as in the control group (Table 2). Comparison of right and left ulnar nerve conduction parameters between taxi drivers and the control group is given in Table 3.

Among the non-leaning group of taxi drivers, there was no difference in the median, ulnar, or radial nerve conduction parameters, or minimum $\mathrm{F}$ latencies between the right and left extremities. Among the leaning group of taxi drivers, left ulnar nerve motor and sensory conduction velocities at the elbow segment were significantly slower than those on the right side, while the left ulnar nerve minimum $F$ latencies were significantly longer than the right. Left side motor and sensory conduction velocities of the ulnar nerve at the elbow segment were slower in the leaning group of taxi drivers as compared to the non-leaning group of taxi drivers (Table 4). Comparison of the right and left ulnar nerve conduction parameters in the leaning and nonleaning groups is given in Table 5 .

Examination of the linear relationship between the numerical data showed that as the number of

Table 3. Comparison of ulnar nerve electrophysiological parameters between and within groups

\begin{tabular}{|c|c|c|c|c|c|c|c|c|c|c|c|c|}
\hline \multirow[t]{3}{*}{ Variables } & \multicolumn{6}{|c|}{ Control group } & \multicolumn{6}{|c|}{ Taxi drivers } \\
\hline & \multicolumn{3}{|c|}{ Right } & \multicolumn{3}{|c|}{ Left } & \multicolumn{3}{|c|}{ Right } & \multicolumn{3}{|c|}{ Left } \\
\hline & Mean \pm SD & Median & Min.-Max. & Mean \pm SD & Median & Min.-Max. & Mean \pm SD & Median & Min.-Max. & Mean \pm SD & Median & Min.-Max. \\
\hline DML & & 2.7 & $2.6-2.8$ & & 2.7 & $2.5-2.8$ & & 2.8 & $2.6-3.0$ & & 2.8 & $2.6-3.0$ \\
\hline CMAP & $10.8 \pm 1.6$ & & & $10.0 \pm 2.0$ & & & $10.9 \pm 2.0$ & & & $10.5 \pm 1.8$ & & \\
\hline MCVF & $63.2 \pm 3.5$ & & & $63.7 \pm 4.2$ & & & $62.0 \pm 2.9$ & & & $63.1 \pm 4.5$ & & \\
\hline MCVE & & 68.5 & $64.6-73.1^{15 \neq}$ & & 66.7 & $64.1-72.4^{\dagger \S 9}$ & & 60.05 & $56.4-62.8^{\text {tSキT }}$ & & 53.7 & $47.6-56.3^{\text {t\$干⿻ }}$ \\
\hline MFL & & 26.0 & $25.1-27.0^{*}$ & & 26.3 & $25.1-27.2^{*}$ & & 26.8 & $26.0-27.6$ & & 27.5 & $26.1-28.8^{*}$ \\
\hline DSL & & 2.7 & 2.6-3.0 & & 2.7 & 2.6-2.9 & & 2.8 & 2.7-3.0 & & 2.8 & $2.7-3.0$ \\
\hline SNAP & & 39.6 & $31.8-60.0$ & & 44.1 & $24.7-58.2$ & & 40.0 & $28.0-50.0$ & & 32.8 & 22.3-46.5 \\
\hline SCVF & & 64.4 & 60.1-68.7 & & 64.7 & $62.0-67.6$ & & 62.8 & $60.1-66.7$ & & 64.9 & $61.6-67.8$ \\
\hline SCVE & $69.4 \pm 6.1^{\alpha \beta \mu}$ & & & $69.7 \pm 6.1^{\alpha \beta \varepsilon}$ & & & $60.7 \pm 6.1^{\alpha \beta \mu \&}$ & & & $54.5 \pm 6.4^{\alpha \beta \mu \varepsilon}$ & & \\
\hline
\end{tabular}


Table 4. Comparison of ulnar nerve electrophysiological parameters between the taxi drivers that did and did not lean the left elbow on the edge of the car door

\begin{tabular}{|c|c|c|c|c|c|c|c|c|c|c|c|c|c|c|}
\hline \multirow[t]{3}{*}{ Variables } & \multicolumn{6}{|c|}{ Did not lean elbow } & \multirow[b]{3}{*}{$p^{*}$} & \multicolumn{6}{|c|}{ Leaned elbow } & \multirow[b]{3}{*}{$p^{* *}$} \\
\hline & \multicolumn{3}{|c|}{ Right } & \multicolumn{3}{|c|}{ Left } & & \multicolumn{3}{|c|}{ Right } & \multicolumn{3}{|c|}{ Left } & \\
\hline & Mean \pm SD & Median & Min.-Max. & Mean \pm SD & Median & Min.-Max. & & Mean \pm SD & Median & Min.-Max. & Mean \pm SD & Median & Min.-Max. & \\
\hline DML & & 2.8 & 2.8-3.1 & & 2.8 & $2.5-2.8$ & 0.112 & & 2.7 & $2.6-3.0$ & & 2.8 & $2.6-3.0$ & 0.182 \\
\hline CMAPs & $10.3 \pm 1.2$ & & & $10.7 \pm 1.1$ & & & 0.479 & $11.0 \pm 2.2$ & & & $10.4 \pm 2.0$ & & & 0.061 \\
\hline MCVF & $62.0 \pm 1.7$ & & & $62.4 \pm 2.0$ & & & 0.717 & $62.0 \pm 3.2$ & & & $63.3 \pm 4.9$ & & & 0.121 \\
\hline MCVE & & 57.1 & $56.1-61$ & & 56.8 & $54.5-64.9$ & 0.611 & & 60.5 & $56.4-63.7$ & & 52.4 & $47.1-56.1$ & $<0.001$ \\
\hline MFL & & 26.8 & $25.8-27.7$ & & 26.6 & $25.7-27.4$ & 0.499 & & 26.8 & $26.0-27.6$ & & 27.7 & $26.3-28.8$ & $<0.001$ \\
\hline SNAP & & 44.1 & $30.8-53.4$ & & 31.4 & $22.3-57.5$ & 0.499 & & 39.4 & $24.5-43.3$ & & 33.6 & $22.1-43.8$ & 0.339 \\
\hline SCVF & & 65.5 & $61.3-67.8$ & & 65.5 & $61.5-67.8$ & 1.000 & & 62.7 & $60.0-66.7$ & & 64.4 & $61.0-67.7$ & 0.562 \\
\hline SCVE & $60.7 \pm 4.6$ & & & $60.3 \pm 4.4$ & & & 0.829 & $60.7 \pm 6.4$ & & & $53.2 \pm 6.1$ & & & $<0.001$ \\
\hline
\end{tabular}

years working as a taxi driver and hours worked per week increased, left ulnar nerve motor and sensory conduction velocities at the elbow segment decreased significantly $(p<0.01)$.

Ulnar entrapment neuropathy at the elbow was electrophysiologically diagnosed in nine (22.5\%) taxi drivers of the leaning group ( 1 definite and 8 probable). The condition was not diagnosed in taxi drivers of the non-leaning group. All cases of UNEE were unilateral, two on the right side, and seven on the left side. Four of these nine taxi drivers complained of subjective symptoms without objective sensory or motor deficit of the ulnar nerve. Denervation potentials were observed in the abductor digiti minimi muscle in a taxi driver with probable UNEE.

\section{DISCUSSION}

Ulnar entrapment neuropathy at the elbow was described by Hagberg et al. ${ }^{11}$ as the second most leading occupational upper-limb nerve entrapment after carpal tunnel syndrome. The prevalence of UNEE has been reported to vary from $2.8 \%$ among workers whose occupations require repetitive work to $6.8 \%$ in floor cleaners. ${ }^{12,13}$

Although the literature contains only a few studies on work-related ulnar entrapment neuropathy, a high prevalence among some professions in particular has been reported. The rate of ulnar nerve involvement was reported as $40 \%$ of musicians $(n=69)$ and $42.5 \%$ of workers operating vibrating tools $(n=167)$, although they had only asymptomatic across-elbow ulnar nerve conduction delay. ${ }^{14,15}$ Nainzadeh et al. ${ }^{16}$ reported that UNEE was identified in 105 out of 148 computer keyboard operators, referred for electrodiagnosis due to clinical suspicion of focal upper limp neuropathies. Descatha et al. ${ }^{12}$ found 15 incident cases of UNEE among 598 industrial workers during a three-year follow-up, and these resulted in an estimated incidence of $8.4 / 1,000$

Table 5. Comparison of ulnar nerve electrophysiological parameters between taxi drivers that did and did not lean the left elbow on the edge of the car door

\begin{tabular}{|c|c|c|c|c|c|c|c|c|c|c|c|c|}
\hline \multirow[t]{3}{*}{ Variables } & \multicolumn{6}{|c|}{ Did not lean elbow } & \multicolumn{6}{|c|}{ Leaned elbow } \\
\hline & \multicolumn{3}{|c|}{ Right } & \multicolumn{3}{|c|}{ Left } & \multicolumn{3}{|c|}{ Right } & \multicolumn{3}{|c|}{ Left } \\
\hline & Mean \pm SD & Median & Min.-Max. & Mean \pm SD & Median & Min.-Max. & Mean \pm SD & Median & Min.-Max. & Mean \pm SD & Median & n Min.-Max. \\
\hline DML & & 2.8 & $2.8-3.1$ & & 2.8 & $2.5-2.8$ & & 2.7 & $2.6-3.0$ & & 2.8 & $2.6-3.0$ \\
\hline CMAPs & $10.3 \pm 1.2$ & & & $10.7 \pm 1.1$ & & & $11.0 \pm 2.2$ & & & $10.4 \pm 2.0$ & & \\
\hline MCVF & $62.0 \pm 1.7$ & & & $62.4 \pm 2.0$ & & & $62.0 \pm 3.2$ & & & $63.3 \pm 4.9$ & & \\
\hline MCVE & & 57.1 & $56.1-61^{1 \S}$ & & 56.8 & $54.5-64.9^{t \neq}$ & & 60.5 & $56.4-63.7$ & & 52.4 & $47.1-56.1^{1 \S \ddagger}$ \\
\hline MFL & & 26.8 & $25.8-27.7^{\alpha \beta}$ & & 26.6 & $25.7-27.4^{\alpha \infty}$ & & 26.8 & $26.0-27.6$ & & 27.7 & $26.3-28.8^{\alpha \beta \infty}$ \\
\hline DSL & & 2.9 & 2.8-3.0 & & 2.7 & $2.7-2.9$ & & 2.8 & $2.7-3.0$ & & 2.8 & $2.8-3.0$ \\
\hline SNAP & & 44.1 & $30.8-53.4$ & & 31.4 & $22.3-57.5$ & & 39.4 & $24.5-43.3$ & & 33.6 & $22.1-43.8$ \\
\hline SCVF & & 65.5 & $61.3-67.8$ & & 65.5 & $61.5-67.8$ & & 62.7 & $60.0-66.7$ & & 64.4 & $61.0-67.7$ \\
\hline SCVE & $60.7 \pm 4.6^{* \#}$ & & & $60.3 \pm 4.4^{* \mu}$ & & & $60.7 \pm 6.4$ & & & $53.2 \pm 6.1^{* *_{\mu}}$ & & \\
\hline
\end{tabular}


person-years. Descatha et al. ${ }^{12}$ reported that the major risk factors for UNEE were obesity, repetitive actions, and working at a stable position.

It has been reported that external and internal pressure on the ulnar nerve might occur in drivers as a result of prolonged elbow flexion and leaning the elbow on the lower edge of the window; ${ }^{17}$ however, controlled studies have not been conducted to confirm this hypothesis. Abdel-Salam et al. ${ }^{18}$ reported three truck drivers diagnosed with UNEE. To the best of our knowledge, the present study is the first controlled study on UNEE in taxi drivers and the relationship between UNEE and habitually leaning the elbow on the lower edge of the window.

In the taxi driver group, the right and left side ulnar nerve motor and sensory conduction velocities at the elbow segment were slower, and the minimum $F$ latencies were longer than those in the control group. Moreover, the left side ulnar nerve motor and sensory conduction velocities at the elbow segment were slower, and the minimum $\mathrm{F}$ latencies were longer than those on the right side in the taxi driver group. The bilateral nature of the findings might have been because the drivers' right and left elbows were exposed to long-term flexion while handling the steering-wheel, and because of repetitive flexion and extension at the right elbow while shifting gears. The additional effect of compression caused by leaning the left elbow on the lower edge of the window may also be a cause, all independent of the dominant side. As we expected, the ulnar nerve was affected due to long-term flexion of the left elbow in the taxi driver group as evidenced by slower motor and sensory conduction velocities and longer F latencies on the left side than on the right side. Increased cubital tunnel pressures with elbow flexion have been reported in clinical studies. ${ }^{19}$ Elbow flexion may cause cubital tunnel flattening, increasing the pressure and decreasing the blood supply. ${ }^{20}$ Flexion enlarges the space between the olecranon and the medial epicondyle, increases the Osborne ligament's tension, and compresses the ulnar nerve. ${ }^{21}$

Furthermore, in addition to the long-term flexion, the mechanical pressure caused by leaning the elbow was also considered in this present study. Thus, in addition to the long-term flexion, the mechanical pressure caused by leaning the elbow was also taken into consideration. Among the leaning group of taxi drivers, ulnar nerve motor and sensory conduction velocities on the left side at the elbow segment were slower and the minimum $F$ latencies were longer than those on the right side. Moreover, all taxi drivers diagnosed electrophysiologically as having UNEE were included in the leaning group. The right and left side ulnar nerve conduction parameters and the minimum $F$ latencies in the non-leaning group of taxi drivers were statistically similar. This effect can be explained by the long-term elbow flexion and the exposure of the ulnar nerve to direct pressure at the left in relation to the results of the previous studies. ${ }^{18,22}$ Comparison of taxi drivers with healthy controls demonstrated that the more salient effect on the left ulnar nerve in subjects leaning their elbows, the more pronounced effect of direct mechanical pressure. This is unlike the slowed down ulnar nerve motor and sensory conduction velocity at the elbow segment at both sides and the longer minimum $F$ latencies, suggesting that the ulnar nerve was affected due to both elbows being in long-term flexion while handling the steeringwheel and repetitive flexion and extension actions at the right elbow while shifting the gear. In addition to mechanical pressure, shoulder abduction accompanying elbow traction while leaning the left elbow on the lower edge of the window causes an increase in ulnar nerve traction and intraneural pressure. ${ }^{18,23,24}$ With the shoulder abducted, elbow flexed and the forearm pronated, as in the driving position described, the ulnar nerve is clearly at risk. The damage arises from external pressure on the window-sill and from the physiological pressure from the deformed arcuate ligament, accentuated by the persistent vibration from the road surface. ${ }^{18}$

It should not be forgotten that risk factors regarding the professional and personal activities are related to the frequency and duration of the action. ${ }^{17}$ Descatha et al. ${ }^{12}$ reported that the frequency of UNEE increased as the number of years worked increased. A study conducted with engineers reported that increased hours worked per day increased the risk of upper extremity entrapment neuropathy, and that daily rest periods lowered the risk. ${ }^{25}$ 
In the present study, a significant decrease in left ulnar nerve motor and sensory conduction velocities at the elbow segment in the taxi driver group was observed as the number of years as a taxi driver and hours worked per week increased.

The relationship between the side of the lesion and the side of the leaning elbow are compatible as seen. The potential for ulnar nerve damage due to shifting gears with the right arm, in addition to repetitive and long-term right and left elbow flexion while driving must not be overlooked. According to results of the present study, the right elbow was affected by repetitive movement, and long-term left elbow flexion caused a reduction in nerve conduction velocity, primarily due to direct compressive pressure and resultant prolonged $\mathrm{F}$ latency response.

In conclusion, the present study shows that electrodiagnostically diagnosed UNEE may develop in taxi drivers who habitually lean their elbow on the lower edge of the window. However, further large-scale studies are required to definitively define UNEE as an occupational disorder in taxi drivers.

\section{Declaration of conflicting interests}

The authors declared no conflicts of interest with respect to the authorship and/or publication of this article.

\section{Funding}

The authors received no financial support for the research and/or authorship of this article.

\section{REFERENCES}

1. Katirii B. The clinical electromyography examination. An overview. Neurol Clin 2002;20:291-303.

2. Bartels RH, Verbeek AL. Risk factors for ulnar nerve compression at the elbow: a case control study. Acta Neurochir (Wien) 2007;149:669-74.

3. Mondelli M, Giannini F, Ballerini M, Ginanneschi F, Martorelli E. Incidence of ulnar neuropathy at the elbow in the province of Siena (Italy). J Neurol Sci 2005;234:5-10.

4. Novak CB, Mehdian H, von Schroeder HP. Laxity of the ulnar nerve during elbow flexion and extension. $\mathrm{J}$ Hand Surg Am 2012;37:1163-7.

5. Cutts S. Cubital tunnel syndrome. Postgrad Med J 2007;83:28-31.
6. Charness ME. Unique upper extremity disorders of musicians. In: Millender LH, Louis DS, Simmons BD, editors. Occupational disorders of the upper extremity. New York: Churchill Livingstone; 1992. p. 227-52.

7. Bozentka DJ. Cubital tunnel syndrome pathophysiology. Clin Orthop Relat Res 1998;351:90-4.

8. McPherson SA, Meals RA. Cubital tunnel syndrome. Orthop Clin North Am 1992;23:111-23.

9. Robertson C, Saratsiotis J. A review of compressive ulnar neuropathy at the elbow. J Manipulative Physiol Ther 2005;28:345.

10. Campbell WW, Greenderg MK, Krendel DA, Pridgeon RM, Sitaram KP, Williams FH. The electrodiagnostic evaluation of patients with ulnar neuropathy at the elbow: Literature review of the usefulness of nerve conduction studies and electromyography. Muscle Nerve 1999;22(Supl 8):175-205.

11. Hagberg M, Silverstein BA, Wells R, Smith MJ, Herbert $\mathrm{R}$, Hendrick HW, et al. Work related musculoskeletal disorders (WMSDs): A reference book for prevention. 2nd ed. Bristol: Taylor and Francis; 1997.

12. Descatha A, Leclerc A, Chastang JF, Roquelaure Y; Study Group on Repetitive Work. Incidence of ulnar nerve entrapment at the elbow in repetitive work. Scand J Work Environ Health 2004;30:234-40.

13. Mondelli M, Grippo A, Mariani M, Baldasseroni A, Ansuini R, Ballerini M, et al. Carpal tunnel syndrome and ulnar neuropathy at the elbow in floor cleaners. Neurophysiol Clin 2006;36:245-53.

14. Kákosy T. Tunnel syndromes of the upper extremities in workers using hand-operated vibrating tools. Med Lav 1994;85:474-80.

15. Charness ME, Ross MH, Shefner JM. Ulnar neuropathy and dystonic flexion of the fourth and fifth digits: clinical correlation in musicians. Muscle Nerve 1996;19:431-7.

16. Nainzadeh NK, Ilizarov S, Piligian G, Dropkin J, Breyre A. Ulnar neuropathy at the elbow in computer keyboard operators. Work 2011;39:93-101.

17. Armstrong TJ. Cumulative travma disorders of the upper limb and identification of work-related factors. In: Millender LH, Louis DS, Simons BP, editors. Occupational disorders of the upper extremity. New York: Churchill Livingstone; 1992. p. 19-45.

18. Abdel-Salam A, Eyres KS, Cleary J. Drivers' elbow: a cause of ulnar neuropathy. J Hand Surg Br 1991;16:436-7.

19. Colak T, Bamaç B, Ozbek A, Budak F, Bamaç YS. Nerve conduction studies of upper extremities in tennis players. Br J Sports Med 2004;38:632-5.

20. Richardson JK, Jamieson SC. Cigarette smoking and ulnar mononeuropathy at the elbow. Am J Phys Med Rehabil 2004;83:730-4.

21. Özdolap S, Emre U, Karamercan A, Sarikaya S, Köktürk F. Upper limb tendinitis and entrapment neuropathy in coal miners. Am J Ind Med 2013;56:569-75.

22. Mansukhani KA, D'Souza C. Ulnar neuropathy at the elbow in diamond assorters. Indian $\mathrm{J}$ Med Res 1991;94:433-6. 
23. Pechan J, Julis I. The pressure measurement in the ulnar nerve. A contribution to the pathophysiology of the cubital tunnel syndrome. $\mathrm{J}$ Biomech 1975;8:75-9.

24. Jones RE, Gauntt C. Medial epicondylectomy for ulnar nerve compression syndrome at the elbow. Clin Orthop Relat Res 1979;174-8.

25. Conlon CF, Rempel DM. Upper extremity mononeuropathy among engineers. J Occup Environ Med 2005;47:1276-84. 